\title{
Aerodynamic Model for Tandem Flapping Wings
}

DOI:

10.2514/1.J055178

\section{Document Version}

Accepted author manuscript

Link to publication record in Manchester Research Explorer

\section{Citation for published version (APA):}

Anwahi, F., \& Filippone, A. (2016). Aerodynamic Model for Tandem Flapping Wings. AlAA Journal. https://doi.org/10.2514/1.J055178

\section{Published in:}

AIAA Journal

\section{Citing this paper}

Please note that where the full-text provided on Manchester Research Explorer is the Author Accepted Manuscript or Proof version this may differ from the final Published version. If citing, it is advised that you check and use the publisher's definitive version.

\section{General rights}

Copyright and moral rights for the publications made accessible in the Research Explorer are retained by the authors and/or other copyright owners and it is a condition of accessing publications that users recognise and abide by the legal requirements associated with these rights.

\section{Takedown policy}

If you believe that this document breaches copyright please refer to the University of Manchester's Takedown Procedures [http://man.ac.uk/04Y6Bo] or contact uml.scholarlycommunications@manchester.ac.uk providing relevant details, so we can investigate your claim.

\section{OPEN ACCESS}




\title{
Aerodynamic Model for Tandem Flapping Wings
}

\author{
A. H. M. Faisal* and A. Filippone ${ }^{\dagger}$ \\ University of Manchester, Manchester M13 9PL, United Kingdom
}

\begin{abstract}
An aerodynamic model for tandem flapping wings is proposed. The model attempts to represent insects such as the dragonfly. Two advances are presented: the aerodynamic model with tandem wings flapping simultaneously, and the wing stroke optimization. The aerodynamic model accounts for the inflow effects of the front wing (fore-wing) on the rear wing (hind-wing). The stroke is optimized at two flight conditions (acceleration and level flight) by using a heuristic optimization procedure (particle swarming). The vector of the design variables consists of 28 independent parameters (14 per wing), each with a constrained range derived from the maximum available power, the flight muscle ratio and kinematics of real insects. The cost function is the propulsive efficiency coupled with constraints for flight stability. Prediction of the level flight efficiency is in agreement with the flight muscle efficiency. The maximum acceleration is found to be dependent on the size of the flight muscle. Finally, a study of the wing shape is presented for both level and accelerating flight conditions.
\end{abstract}

\section{Nomenclature}

$$
\begin{array}{ll}
a_{u} & =\text { wing relative acceleration, } y \text {-axis } \\
a_{v} & =\text { wing relative acceleration, } z \text {-axis } \\
b_{t} & =\text { wing thickness } \\
c(r) & =\text { wing chord } \\
c(\hat{r}) & =\text { normalized chord } \\
\bar{c} & =\text { mean chord length } \\
C_{d} & =\text { drag coefficient } \\
C_{d}(0) & =\text { drag coefficient at } \alpha=0 \text { degree } \\
C_{d}(\pi / 2) & =\text { drag coefficient at } \alpha=90 \text { degrees } \\
C_{l} & =\text { lift coefficient } \\
C_{r} & =\text { wing rotational lift coefficient } \\
C_{t} & =\text { wing translational lift coefficient } \\
C_{y} & =\text { horizontal force coefficient } \\
C_{z} & =\text { vertical force coefficient } \\
C_{\eta} & =\text { rate of the wing rotation } \\
d r & =\text { wing section } \\
d t & =\text { time step } \\
D & =\text { drag } \\
f & =\text { frequency (motion frequency) }
\end{array}
$$

\footnotetext{
${ }^{*}$ Tutor, Department of Aerospace Engineering, University Putra Malaysia; currently Ph.D. Student, School of Mechanical, Aerospace and Civil Engineering, University of Manchester. Student Member AIAA.

${ }^{\dagger}$ Reader, School of Mechanical, Aerospace and Civil Engineering, University of Manchester. AIAA Senior Member.
} 


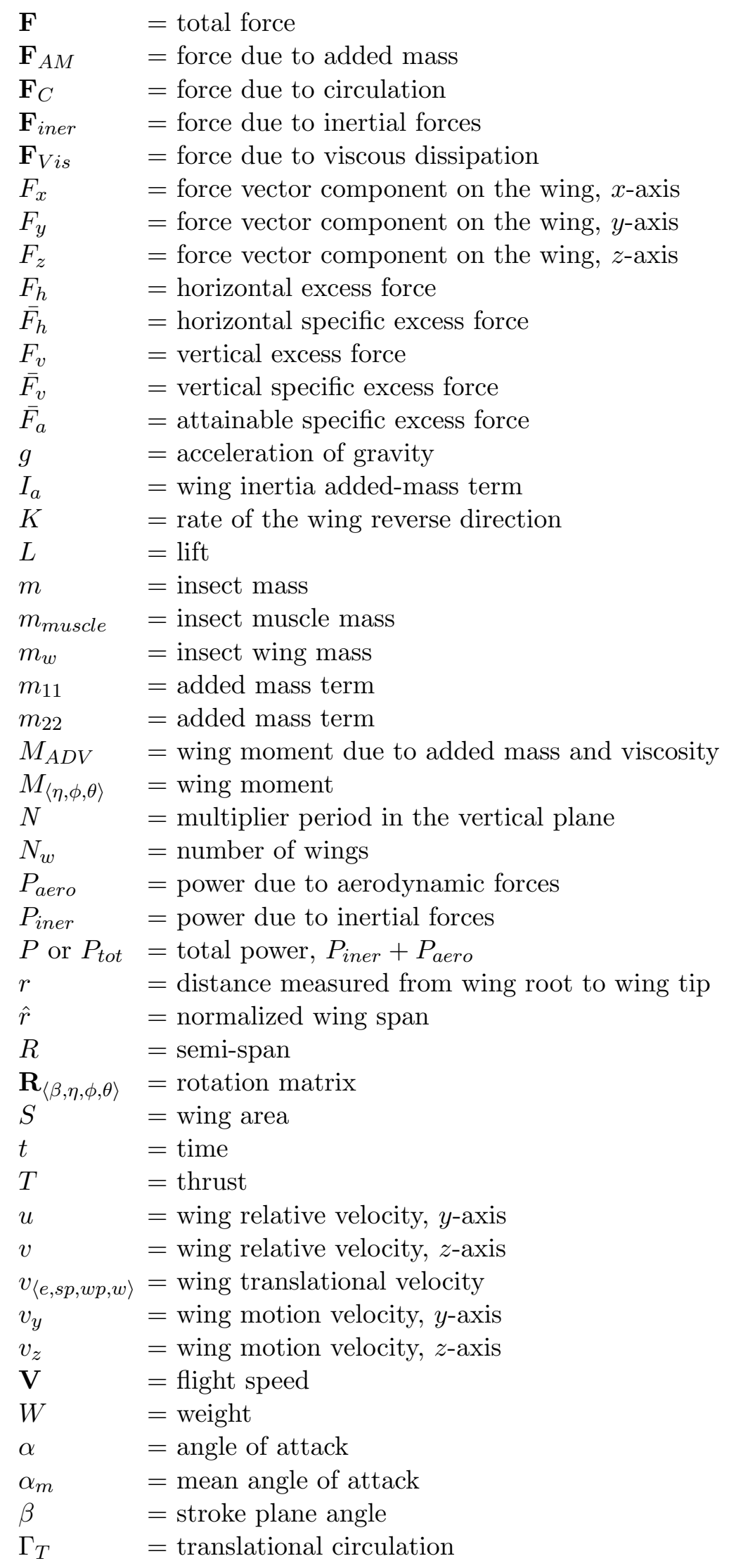




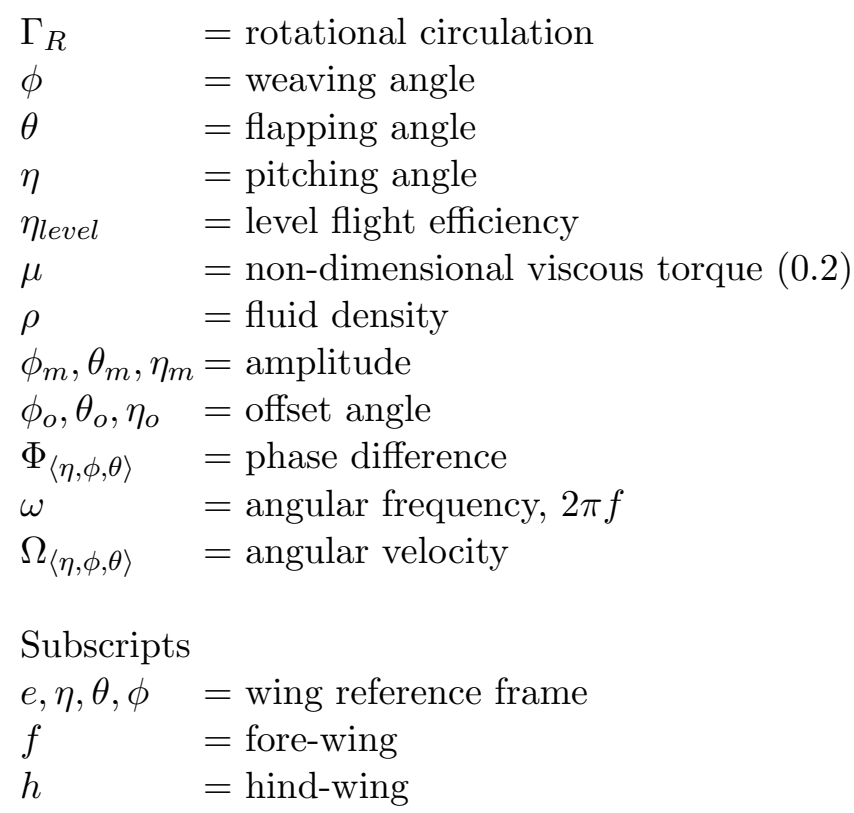

\section{Introduction}

At present there is considerable interest in the physics of flight at very small scale. This interest is a mix of fascination with insect flight and the technology drive to design smaller and smaller flying platforms. Nature-inspired flight is one of the avenues being explored. For example, the dragonfly can routinely accelerate with a $3 g$ rate to a speed of $10 \mathrm{~m} / \mathrm{s}$ on its own body muscles ${ }^{1 ; 2}$, and is capable of generating an instantaneous lift five times greater than its weight ${ }^{3}$. Each of its wings can be actuated independently ${ }^{2 ; 4}$; this allows greater maneuverability at a fraction of the energy required by other insects of comparable mass ${ }^{5}$. Marden ${ }^{6}$ recorded that the flight-muscle growth of the dragonfly is approximately double its body mass during adult maturation.

Most of the research on dragonflies has focused on flight characteristics ${ }^{1 ; 5 ; 6}$ and its relation to the wing configuration ${ }^{7 ; 8 ; 9}$. There are studies on the kinematic variations ${ }^{4 ; 10}$ and the flow interaction ${ }^{11 ; 12 ; 13}$. The study of Wang \& Russell ${ }^{14}$ on the effect of the fore- and hind-wing interactions has shown that the dragonfly would use minimum power to generate the required force in hovering flight. Lehmann ${ }^{15}$ published a study of the wing-wake interaction of wings in tandem configuration and contended that the aerodynamic efficiency can be enhanced by recovering energy from the wake. A further review of tandem and biplane wings was shown by Platzer et al. ${ }^{16}$, where the authors observe that biplane configurations are not present in nature, possibly due to poor efficiency in hover flight.

Aerodynamic models for tandem wings are somewhat limited by the computing times required. 
Since the flapping wing can be regarded as a case of moving boundary problem, body-fitted or unstructured-grid methods are employed in computational fluid dynamic solutions ${ }^{17}$. The experimental work of Warkenting \& DeLaurier ${ }^{18}$, inspired by the dragonfly, included a parametric study of various flapping tandem configurations without parameter optimization, and concluded that asymmetric flapping is inefficient. However, the experiments highlight the fact that the large number of degrees of freedom needs exploring with rational methods.

This paper contributes a low-order aerodynamic model that is able to couple both fore- and hind-wing together and to account for the interaction of the flow, particularly the fact that the hindwing operates in the slipstream of the fore-wing. We introduce an aerodynamic model expanded from an earlier contribution ${ }^{19}$ whilst retaining a reduced level of computational cost.

The estimation of the optimum kinematic parameters for the wing is obtained via a particle swarm optimization ${ }^{20}$. Each of the design variables is subjected to a constrained range derived from experimental studies of the dragonfly ${ }^{5 ; 6 ; 21}$. The cost function of the optimization is the propulsive efficiency coupled with constraints for flight stability.

\section{Wing Aerodynamic Model}

This section describes the mathematical model for fore- and hind-wing in multiple wing design configuration. Since this method is fully described in a previous paper ${ }^{19}$, only a brief explanation of the method is presented, along with the developments arising from the tandem-wing configuration.

\section{A Wing Geometry}

An elliptical function (tear-drop shape) is used for the fore- and hind-wing shape:

$$
c(r)=\frac{4 \bar{c}}{\pi} \sqrt{1-\frac{r^{2}}{R^{2}}}
$$

where $\bar{c}$ is the mean chord length, $R$ is the wing length, and $r$ is the radial distance measured from the root to the wing tip. The reference chords and spans (radii) of the wings are given in Table 1.

Table 1: Mean chord length $\bar{c}$ and wing length $R$ of the dragonfly fore- and hind wing.

\begin{tabular}{c|cc}
\hline & $\bar{c}(\mathrm{~mm})$ & $R(\mathrm{~mm})$ \\
\hline Fore-Wing & 5.88 & 27.85 \\
Hind-Wing & 7.68 & 26.90 \\
\hline
\end{tabular}


In order to have the closest similarity to an insect wing (real wing shape), a set of polynomials is used to approximate the dragonfly wing planform. The new equation is derived from the analysis of the digital photograph shown in Fig. 1.

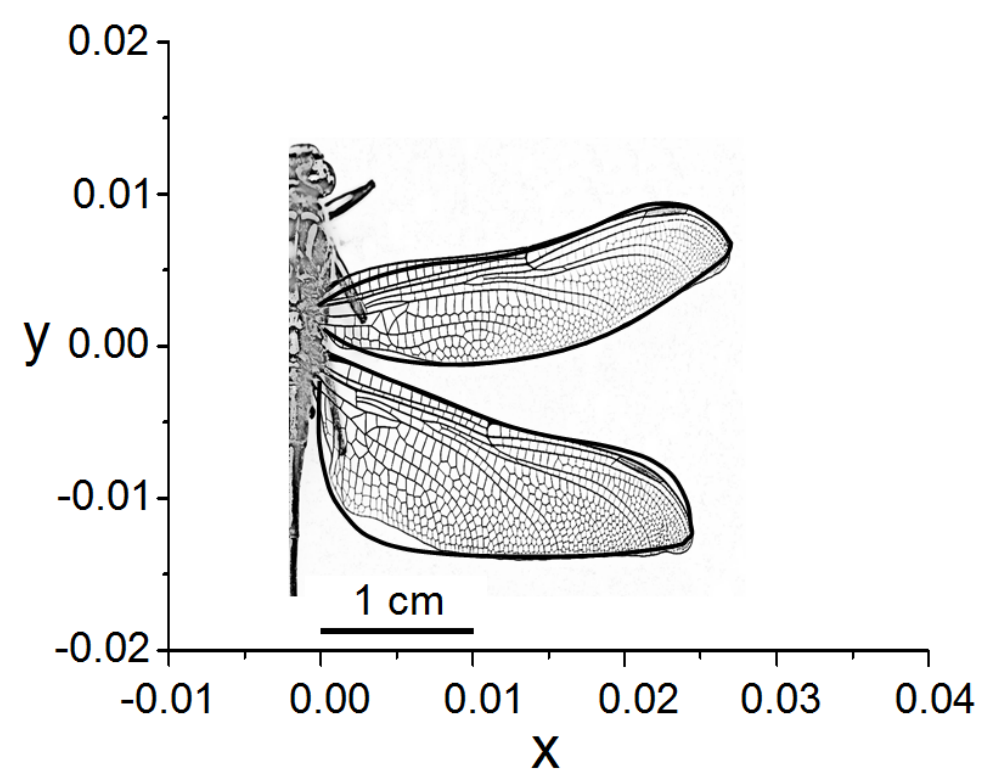

Figure 1: Dragonfly wing. The thick solid line represents the wing derived from Eq. 2.

$$
c(\hat{r})=a+b \hat{r}+c \hat{r}^{2}+d \hat{r}^{3}+e \hat{r}^{4}+f \hat{r}^{5}
$$

where $c(\hat{r})$ is the normalized chord and $\hat{r}$ is the normalized wing span. For each wing, the polynomial coefficients are grouped into two sections, representing the upper and lower part of the wings, respectively. The corresponding coefficients for each part of the wing sections are given in Table 2 .

Table 2: Coefficients of the polynomial Eq. 2.

\begin{tabular}{rrrrr}
\hline & \multicolumn{2}{c}{ Fore-Wing } & \multicolumn{2}{c}{ Hind-Wing } \\
\hline & Upper & Lower & Upper & Lower \\
\hline$a$ & 0.0154 & -0.0273 & 0.0321 & -0.0144 \\
$b$ & 0.4146 & -1.0711 & -0.0206 & -2.6763 \\
$c$ & -0.4984 & 3.1849 & 0.9173 & 7.6848 \\
$d$ & -2.6774 & -5.5107 & -4.0000 & -8.9040 \\
$e$ & 6.7850 & 5.2309 & 6.8385 & 4.5981 \\
$f$ & -4.0250 & -1.8304 & -3.7509 & -0.7086 \\
\hline
\end{tabular}




\section{B Wing Kinematics}

A parametrized kinematics model is applied in describing the fore- and hind wing motions ${ }^{22}$. There are three angular movements: weaving $\phi$, back and forward in the horizontal plane; flapping $\theta$ in the vertical plane; pitching $\eta$ is the rotating angle about a span-wise axis (axis lies at mid-section of the chord). These angles are calculated from

$$
\begin{gathered}
\phi(t)=\frac{\phi_{m}}{\sin ^{-1}(K)} \sin ^{-1}\left[K \sin \left(2 \pi f t+\Phi_{\phi}\right)\right]+\phi_{0} \\
\theta(t)=\theta_{m} \cos \left(2 \pi N f t+\Phi_{\theta}\right)+\theta_{0} \\
\eta(t)=\frac{\eta_{m}}{\tanh \left(C_{\eta}\right)} \tanh \left[C_{\eta} \sin \left(2 \pi f t+\Phi_{\eta}\right)\right]+\eta_{0}
\end{gathered}
$$

\section{Coordinate Definitions and Transformation}

The wing is assumed to move freely as a thin rigid flat plate pinned at the root, with the flapping kinematics realized by rotations about a fixed joint. The rotation and the translation of fore(subscript $f$ ) and hind wing (subscript $h$ ) are calculated using a rotation matrix

$$
(\mathbf{R})_{\langle f, h\rangle}=\left(\mathbf{R}_{\beta}\right)_{\langle f, h\rangle}\left(\mathbf{R}_{\theta}\right)_{\langle f, h\rangle}\left(\mathbf{R}_{\phi}\right)_{\langle f, h\rangle}\left(\mathbf{R}_{\eta}\right)_{\langle f, h\rangle}
$$

where

$$
\begin{aligned}
\mathbf{R}_{\beta} & =\left(\begin{array}{ccc}
1 & 0 & 0 \\
0 & \cos \beta & \sin \beta \\
0 & -\sin \beta & \cos \beta
\end{array}\right), \mathbf{R}_{\theta}=\left(\begin{array}{ccc}
\cos \theta & 0 & -\sin \theta \\
0 & 1 & 0 \\
\sin \theta & 0 & \cos \theta
\end{array}\right) \\
\mathbf{R}_{\phi} & =\left(\begin{array}{ccc}
\cos \phi & \sin \phi & 0 \\
-\sin \phi & \cos \phi & 0 \\
0 & 0 & 1
\end{array}\right), \mathbf{R}_{\eta}=\left(\begin{array}{ccc}
1 & 0 & 0 \\
0 & \cos \eta & -\sin \eta \\
0 & \sin \eta & \cos \eta
\end{array}\right)
\end{aligned}
$$

The local position of the fore- and hind-wing from the earth axes (subscript $e$ ) to the blade element axes (subscript $\eta$ ) can be transformed via a rotation matrix

$$
\mathbf{p}_{\eta\langle f, h\rangle}=(\mathbf{R})_{\langle f, h\rangle} \mathbf{p}_{e\langle f, h\rangle}
$$

The local velocity of the wing can be evaluated numerically using a finite difference approximation of Eq. (8) at times $t$ and $t+\Delta t$ over a period $T$. 


\section{Aerodynamic Forces}

The forces on each element of the wing with respect to the $\eta$ reference frame (Figure 2) are calculated via numerical integration.

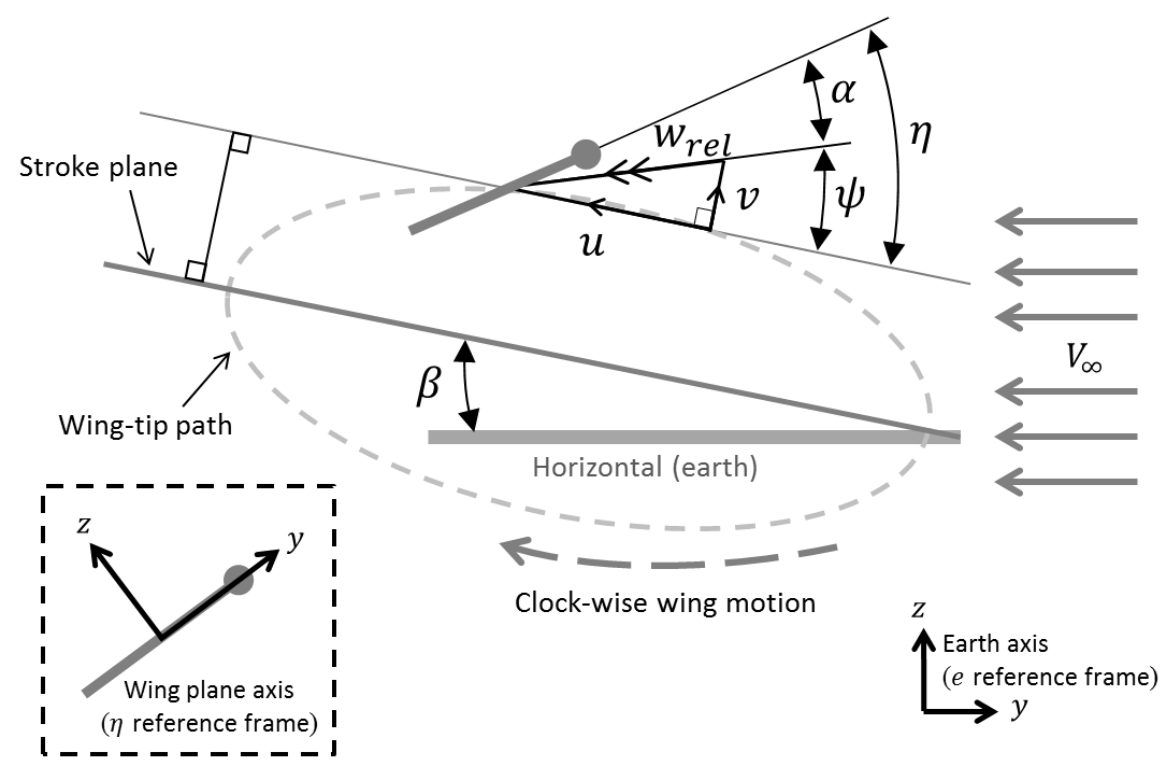

Figure 2: Flow geometry for blade element at radial station $r$.

$$
\left\{\begin{array}{l}
\left(\mathbf{F}_{\eta, \text { aero }}\right)_{\langle f, h\rangle}=\left(\mathbf{F}_{C}\right)_{\langle f, h\rangle}+\left(\mathbf{F}_{A M}\right)_{\langle f, h\rangle}+\left(\mathbf{F}_{V i s}\right)_{\langle f, h\rangle} \\
\left(\mathbf{F}_{\eta, \text { iner }}\right)_{\langle f, h\rangle}=\left(\mathbf{F}_{\text {iner }}\right)_{\langle f, h\rangle}
\end{array}\right.
$$

This is a summation of four force components: the force due to circulation $\left(\mathbf{F}_{C}\right)_{\langle f, h\rangle}$; the wing inertia $\left(\mathbf{F}_{\text {iner }}\right)_{\langle f, h\rangle}$; the added mass $\left(\mathbf{F}_{A M}\right)_{\langle f, h\rangle}$; the viscous dissipation $\left(\mathbf{F}_{V i s}\right)_{\langle f, h\rangle}$. The force components $(y, z)$ for both fore- and hind-wing are

$$
\begin{aligned}
& \left\{\begin{array}{c}
F_{C, y}=\int_{0}^{R}(-\rho v \Gamma) d r \\
F_{C, z}=\int_{0}^{R}(\rho u \Gamma) d r
\end{array}\right. \\
& \left\{\begin{array}{l}
F_{\text {iner }, y}=\int_{0}^{R}\left(\frac{c(r)}{\bar{c} R} m_{w}\right) v \dot{\eta} d r \\
F_{\text {iner }, z}=-\int_{0}^{R}\left(\frac{c(r)}{\bar{c} R} m_{w}\right) u \dot{\eta} d r
\end{array}\right.
\end{aligned}
$$




$$
\begin{gathered}
\left\{\begin{array}{c}
F_{A M, y}=\int_{0}^{R}\left(m_{22} v \dot{\eta}-m_{11} a_{u}\right) d r \\
F_{A M, z}=-\int_{0}^{R}\left(m_{11} u \dot{\eta}-m_{22} a_{v}\right) d r
\end{array}\right. \\
\left\{\begin{array}{l}
F_{V i s, y}=-\int_{0}^{R} \frac{1}{2} \rho c(r)\left[C_{d}(0) \cos ^{2}(\alpha)+C_{d}(\pi / 2) \sin ^{2}(\alpha)\right]\left(\sqrt{u^{2}+v^{2}}\right) u d r \\
F_{V i s, z}=-\int_{0}^{R} \frac{1}{2} \rho c(r)\left[C_{d}(0) \cos ^{2}(\alpha)+C_{d}(\pi / 2) \sin ^{2}(\alpha)\right]\left(\sqrt{u^{2}+v^{2}}\right) v d r
\end{array}\right.
\end{gathered}
$$

with the circulation $\Gamma$, the added mass terms $m_{11}, m_{22}$ and the wing inertia $I_{a}$ defined by

$$
\begin{gathered}
\Gamma=-\frac{1}{2} C_{t}\left(\sqrt{u^{2}+v^{2}}\right) \sin 2 \alpha c(r)+\frac{1}{2} C_{r} \dot{\eta} c^{2}(r) \\
m_{11}=\frac{1}{4} \pi \rho b_{t}^{2} \quad \text { and } \quad m_{22}=\frac{1}{4} \pi \rho c^{2}(r) \quad \text { and } \quad I_{a}=\frac{1}{128} \pi \rho\left(c^{2}(r)+b_{t}^{2}\right)^{2}
\end{gathered}
$$

where $u$ and $a_{u}$ and $v$ and $a_{v}$ are the $y$-axis and $z$-axis local velocity and acceleration component on the $\eta$ reference frame. The density of the fluid is $\rho=1.225 \mathrm{~kg} / \mathrm{m}^{3}$; the mass is $m=121.9 \times 10^{-6}$ $\mathrm{kg}$; the aerodynamic coefficients are taken from Berman \& $\mathrm{Wang}^{22}$ and Usherwood \& Ellington ${ }^{23}$, as given in Table 3 .

Table 3: Aerodynamic coefficients of the dragonfly fore- and hind-wing.

\begin{tabular}{c|ccc}
\hline & $C_{d}(0)$ & $C_{d}(\pi / 2)$ & $C_{r}$ \\
\hline Fore-Wing & 0.12 & 2.71 & $\pi$ \\
Hind-Wing & 0.14 & 2.85 & $\pi$ \\
\hline
\end{tabular}

The lift due to the wing translation $C_{t}$ is calculated via the extended lifting line theory, adapted from Taha et al. ${ }^{24}$.

The force is transformed from the $\eta$ reference system back to the earth reference system by multiplication of Eq. (9) with the inverse matrix $\left(\mathbf{R}^{-\mathbf{1}}\right)_{\langle f, h\rangle}$

$$
\left(\mathbf{F}_{e}\right)_{\langle f, h\rangle}=\left(\mathbf{R}^{-1}\right)_{\langle f, h\rangle}\left(\mathbf{F}_{w}\right)_{\langle f, h\rangle}
$$

Thus, the net lift to weight ratio $L / W$ from fore- and hind-wing can be determined from

$$
\frac{L}{W}=\frac{N_{w}\left[\left(F_{e, z}\right)_{f}+\left(F_{e, z}\right)_{h}\right]}{m g}
$$


where $N_{w}$ is the number of wings, and $g=9.81 \mathrm{~m} / \mathrm{s}^{2}$ is the acceleration of gravity. By multiplying the respective forces with their moment-arms, the moments $\left(M_{x}, M_{y}, M_{z}\right)$ are obtained. The power due to aerodynamic and inertia effects can be determined by multiplying the respective moments with the angular rotations $\left(\Omega_{\eta}, \Omega_{\theta}\right.$ and $\left.\Omega_{\phi}\right)$

$$
\left\{\begin{array}{l}
P_{\text {aero }}=N_{w} \oint\left|M_{x} \Omega_{\eta}+M_{y} \Omega_{\theta}+M_{z} \Omega_{\phi}\right|_{\text {aero }} \\
P_{\text {iner }}=N_{w} \oint\left|M_{x} \Omega_{\eta}+M_{y} \Omega_{\theta}+M_{z} \Omega_{\phi}\right|_{\text {iner }}
\end{array}\right.
$$

Finally, the total power resultant from both fore- and hind-wing is

$$
P=\left(P_{\text {aero }}+P_{\text {iner }}\right)_{f}+\left(P_{\text {aero }}+P_{\text {iner }}\right)_{h}
$$

\section{E Induced Velocity}

The interaction between the fore-wing on the hind-wing is modeled via some induction factors, as shown in Fig. 3. The inflow angle of the fore-wing is estimated from

$$
\psi_{f}=\tan ^{-1}\left(\frac{v_{f}}{u_{f}}\right)=\tan ^{-1} \frac{v_{z}\left(1+a_{f}\right)}{v_{y}\left(1-a_{f}^{\prime}\right)}
$$

The hind-wing is affected by the inflow of the fore-wing. The inflow component $v_{z}$ of the hind-wing is multiplied by the axial induced flow factor of the fore-wing according to the following equation:

$$
\psi_{h}=\tan ^{-1}\left(\frac{v_{h}}{u_{h}}\right)=\tan ^{-1} \frac{\left[v_{z}\left(1+a_{f}\right)\right]\left(1+a_{h}\right)}{v_{y}\left(1-a_{h}^{\prime}\right)}
$$

where $u$ and $v$ of both wings are the local velocity components on the $\phi$ reference frame calculated from $\mathbf{V}_{\phi}=\mathbf{R}_{\phi} \mathbf{R}_{\theta} \mathbf{R}_{\beta} \mathbf{V}_{e}$.

The flow of the fore-wing extends downstream and enters the area of influence (or actuator disk) of the hind-wing. It is assumed that the air approaching the hind-wing already has a portion of the fore-wing velocity in the $z$ direction, normal to the stroke plane. This assumption is similar to the experimental results of Gravish et al. ${ }^{25}$, in which the resultant airflow from a pair of wings working together is higher than the total air flow from individual contributions. The axial $(a)$ and radial $\left(a^{\prime}\right)$ induction factors are calculated as shown in Ref. ${ }^{19}$. 


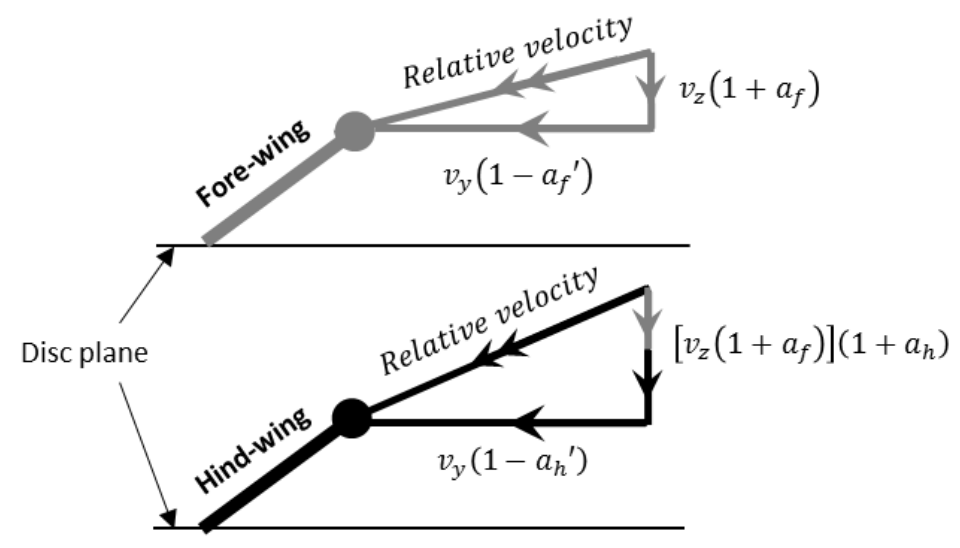

Figure 3: Flow interaction due to the slipstream (induced flow) of the fore-wing on the hind-wing.

\section{F Stroke Optimization}

The optimization of the wing kinematics is carried out with the particle swarming optimization ${ }^{20}$. Here, the chosen cost function are maximum propulsive efficiency for level flight and maximum acceleration for accelerating flight; with constraints on the flight stability, muscular power ratio ${ }^{5}$, flight muscle ratio ${ }^{6}$, and wing kinematics ${ }^{21}$.

Table 4: Range (or constraints) for the optimal model parameters.

\begin{tabular}{c|cc}
\hline Parameter & Fore-Wing & Hind-Wing \\
\hline$f$ & $30.0-45.00 \mathrm{~Hz}$ & $30.0-45.00 \mathrm{~Hz}$ \\
$\phi_{m}$ & $30.0^{\circ}-60.0^{\circ}$ & $30.0^{\circ}-60.0^{\circ}$ \\
$\theta_{m}$ & $1.0^{\circ}-20.0^{\circ}$ & $1.0^{\circ}-20.0^{\circ}$ \\
$\eta_{m}$ & $1.0^{\circ}-90.0^{\circ}$ & $1.0^{\circ}-90.0^{\circ}$ \\
$\phi_{\circ}$ & $-30.0^{\circ}-30.0^{\circ}$ & $-30.0^{\circ}-30.0^{\circ}$ \\
$\theta_{\circ}$ & $5.0^{\circ}-30.0^{\circ}$ & $-30.0^{\circ}--5.0^{\circ}$ \\
$\eta_{\circ}$ & $-90.0^{\circ}-90.0^{\circ}$ & $-90.0^{\circ}-90.0^{\circ}$ \\
$\Phi_{\phi}$ & $-180.0^{\circ}-180.0^{\circ}$ & $-180.0^{\circ}-180.0^{\circ}$ \\
$\Phi_{\theta}$ & $-180.0^{\circ}-180.0^{\circ}$ & $-180.0^{\circ}-180.0^{\circ}$ \\
$\Phi_{\eta}$ & $-180.0^{\circ}-180.0^{\circ}$ & $-180.0^{\circ}-180.0^{\circ}$ \\
$K$ & $0.01-1.00$ & $0.01-1.00$ \\
$N$ & 1 or 2 & 1 or 2 \\
$C_{\eta}$ & $0.01-5.00$ & $0.01-5.00$ \\
$\beta_{m}$ & $5.0^{\circ}-30.0^{\circ}$ & $5.0^{\circ}-30.0^{\circ}$ \\
\hline
\end{tabular}

In level flight, the lift is equal to the weight $(L=W)$ and the thrust is equal to the drag $(T=D)$. In accelerated flight, the lift and thrust are greater than the weight $(L>W)$ and the drag $(T>D)$, respectively. The range for the model parameters of the wing kinematics is given in 
Table 4, following the observation range of data from the experiment by Wakeling \& Ellington ${ }^{21}$.

Furthermore, as to comply with the physical power of the real insect, the available power has to be limited ${ }^{26}$. Following Marden ${ }^{6}$ and Wakeling \& Ellington ${ }^{27}$, the maximum flight muscle ratio $m_{\text {muscle }} / m$ and the available muscular power ratio $P / m_{\text {muscle }}$ can be assumed equal to $60 \%$ and $150 \mathrm{~W} / \mathrm{kg}$, respectively. Hence, by equating these two values, the available power $P / m$ is estimated to be at a maximum of $90 \mathrm{~W} / \mathrm{kg}$.

\section{G Flight Performance}

The level flight efficiency $\eta_{\text {level }}$ can be determined from the relation between the amount of thrust $T$ and power $P$ required,

$$
\eta_{\text {level }}=\frac{T V}{P}
$$

In order to simulate vertically accelerating flight, the sum of the vertical force produced from both wings (fore- and hind-wing) must be greater than the weight. Similarly, the horizontal component of the thrust has to be greater than the drag to accelerate the insect horizontally. The excess vertical and horizontal forces, $F_{v}$ and $F_{h}$, respectively, can be computed from

$$
\begin{gathered}
F_{v}=\left(L_{f}+L_{h}\right)-W \\
F_{h}=D_{f}+D_{h}
\end{gathered}
$$

where $L_{f}, L_{h}$ and $D_{f}, D_{h}$ are the lift and drag forces generated by the fore- and hind-wing, respectively. For convenience, the acceleration is presented in terms of $g$ force. The non-dimensional vertical and horizontal specific excess forces are:

$$
\begin{gathered}
\bar{F}_{v}=\frac{F_{v}}{W} \\
\bar{F}_{h}=\frac{F_{h}}{W}
\end{gathered}
$$

Finally, the attainable specific excess forces $\bar{F}_{a}$ produced can be formulated as

$$
\bar{F}_{a}^{2}=\bar{F}_{v}^{2}+\bar{F}_{h}^{2}
$$




\section{Results and Discussion}

We present the results of tandem flapping wings in level and accelerating flight; we include the analysis of the wing kinematics and the wing shapes on each flight mode.

\section{A Level Flight}

The flight speed range is based on the speed of dragonflies observed by Wakeling \& Ellington ${ }^{21}$, ranging from $0.25 \mathrm{~m} / \mathrm{s}$ up to $2 \mathrm{~m} / \mathrm{s}$, with an increment of $0.25 \mathrm{~m} / \mathrm{s}$.

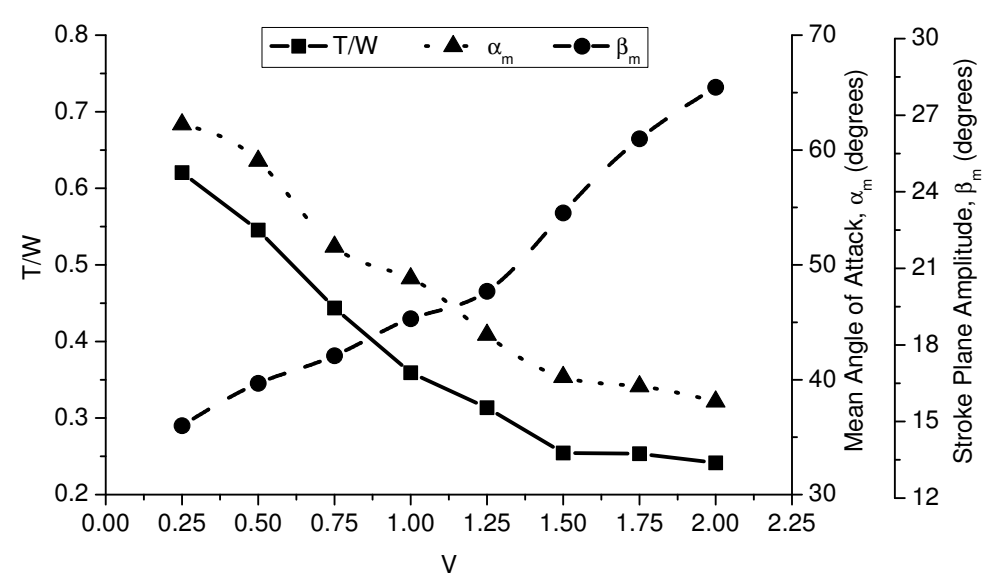

Figure 4: Thrust ratio, mean angle of attack and stroke plane angle of dragonfly in level flight mode.

Figure 4 shows the thrust ratio, mean angle of attack and stroke plane angle of dragonfly in level flight mode (the optimization is applied at each value of $V$ ). The mean angle of attack is calculated based on the average value of both wings over a full flapping period. From this figure, it shows that the wing stroke plane angle increases with the flight speed, whilst the thrust and the wing mean angle of attack are reduced. This reduction in thrust is as indicated by Mazaheri \& Ebrahimi ${ }^{28}$. The changes in these wing angles are consistent with those measured by Azuma $\&$ Watanabe $^{5}$ and Wakeling \& Ellington ${ }^{21}$. With a lower angle of attack, the amount of thrust required to overcome the drag would be lower.

From Fig. 5, the power is reduced to a minimum when the flight speed is $1.5 \mathrm{~m} / \mathrm{s}$. This is similar to the results presented by May ${ }^{1}$ and Azuma \& Watanabe ${ }^{5}$, which was predicted the minimum power to be at a speed between 1 and $2 \mathrm{~m} / \mathrm{s}$. The relationship between the power and the kinematics of the wing could give the best logical correlation in describing the changes of power over the range 


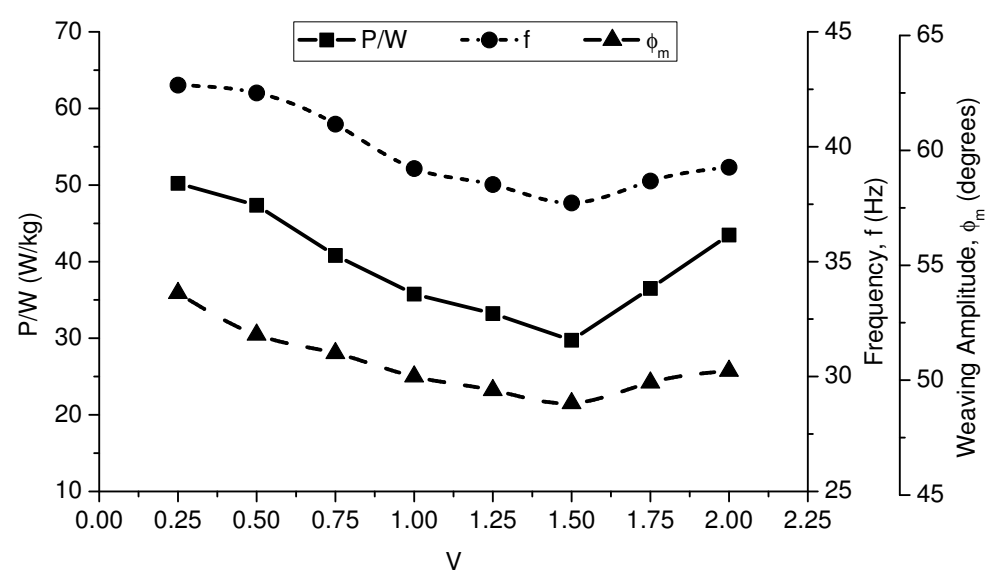

Figure 5: Power ratio, frequency and weaving angle of dragonfly in level flight mode.

of flight speed. The results indicate that the frequency $f$ and the weaving angle $\phi_{m}$ at each speed follow the trend of the predicted power.

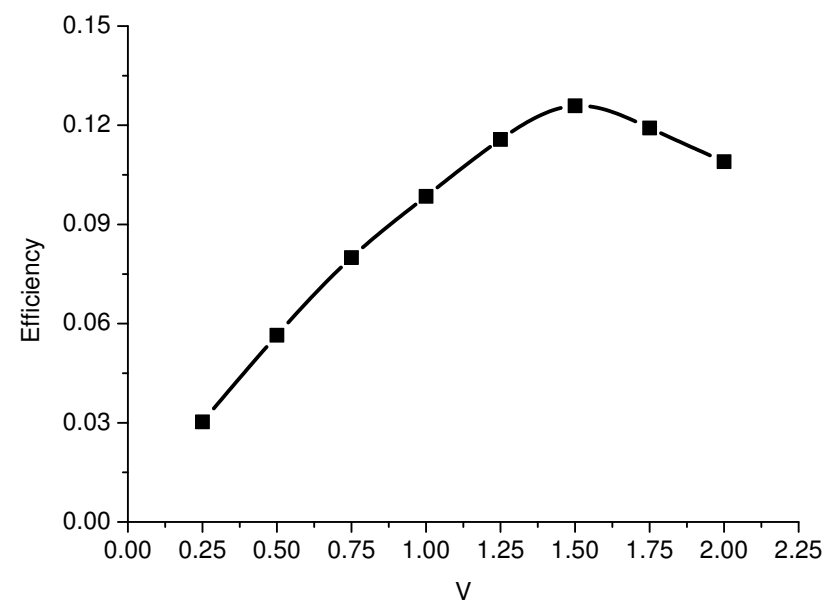

Figure 6: Flight efficiency of dragonfly in level flight mode.

As shown in Fig. 6, the maximum flight efficiency in level flight is predicted to reach $12.7 \%$ at $V=1.5 \mathrm{~m} / \mathrm{s}$. This is in agreement with the flight muscle efficiency measured by Wakeling \& Ellington ${ }^{27}$; these authors provided estimates of $\sim 13 \%$ on the basis of measurements of the thoracic temperature elevation and the thermal conductance of the thorax. 


\section{B Accelerated Flight}

In this section, an analysis is conducted to predict the dragonfly's maximum acceleration. This is to assess claims (Ref. ${ }^{1 ; 2 ; 3}$ ) that the dragonfly would able to generate an enormous amounts of force that can be used for accelerating in such high-speed flight manoeuvres (e.g. take-off or in escape). It is known that the size of the flight muscle is relative to the size, maturation, and species of the insect ${ }^{6 ; 29}$. Here we simulate the maximum acceleration with flight muscle ranging from $30 \%$ to $60 \%$; this equates to power-to-weight ratio between $50 \mathrm{~W} / \mathrm{kg}$ and $90 \mathrm{~W} / \mathrm{kg}$.

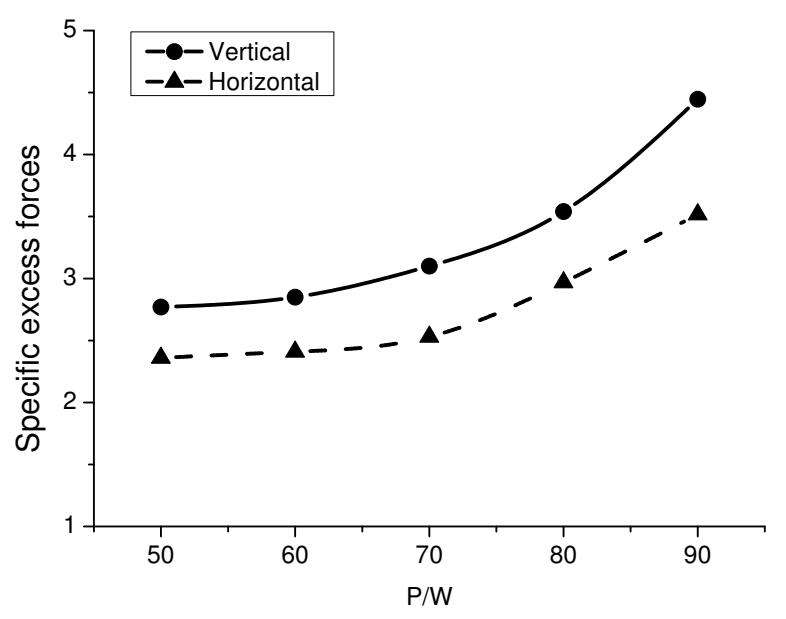

Figure 7: Vertical and horizontal specific excess forces corresponding to the available power.

Figure 7 shows a logical correlation that the vertical and horizontal specific excess forces are increasing with the amount of available power. The vertical specific excess force is 10 to $20 \%$ higher than the horizontal specific excess force for a given power-to-weight ratio. The lowest vertical and horizontal specific excess forces is at $P / W=50 \mathrm{~W} / \mathrm{kg}$ with $\bar{F}_{v} \sim 2.7$ and $\bar{F}_{h} \sim 2.4$, and reaching the highest at $P / W=90 \mathrm{~W} / \mathrm{kg}$ with $\bar{F}_{v} \sim 4.4$ and $\bar{F}_{h} \sim 3.5$.

Figure 8 shows the maximum attainable acceleration increases with the amount of prescribed available power. The predicted $g$ force has a minimum of $\sim 3.6$ and maximum of $\sim 5.6$ at $P / W=$ $50 \mathrm{~W} / \mathrm{kg}$ and $P / W=90 \mathrm{~W} / \mathrm{kg}$, respectively. These values are comparable to the measurements reported in the literature ${ }^{3}$. 


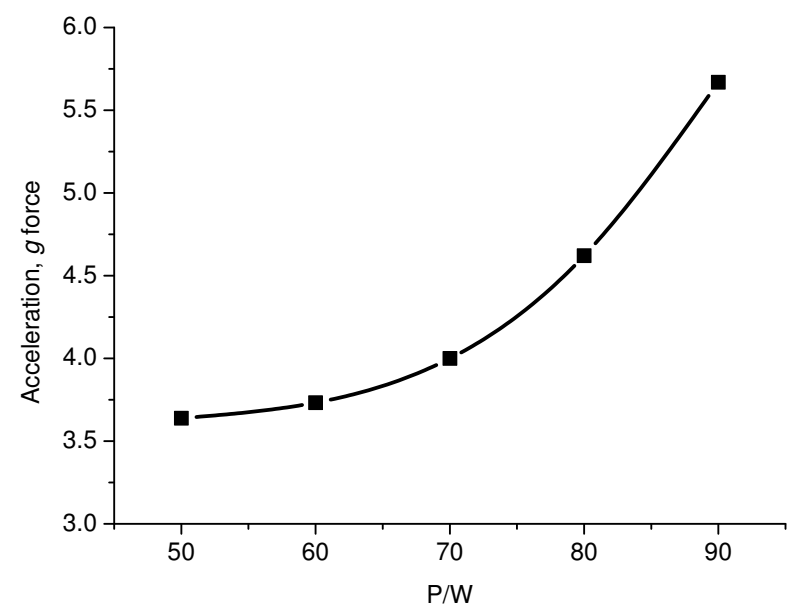

Figure 8: Maximum attainable acceleration corresponding to the amount of available power.

\section{Wing Kinematic Analysis}

An analysis of the wing kinematics for level and accelerating flight modes is shown to validate the model with real insect wing kinematics ${ }^{2 ; 4 ; 21}$. The fore- and hind-wing tip paths relative to the wing base for level and accelerating flights are presented in Fig. 9 and Fig. 10, respectively.

Figure 11 and Fig. 12 show the wing kinematics for the two flight modes. In this analysis, we selected the wing kinematics at $V=1.25 \mathrm{~m} / \mathrm{s}$ for the level flight and at $P / W=60 \mathrm{~W} / \mathrm{kg}$ accelerating flight.

Figure 11(a) indicates that the fore- and hind-wing flap out-of-phase in level flight. The largest phase difference is measured at $V=2 \mathrm{~m} / \mathrm{s}$, at which point the hind-wing leads the fore-wing by 30 degrees. However, as shown in Fig. 11(b) for the accelerating flight, the wings flap in-phase.

Figure 11(c) illustrates the changes in phase for level and accelerating flight modes. These results are in agreement with observations made by Rüppell ${ }^{2} \&$ Alexander $^{4}$, who reported that the dragonfly flap its wings in-phase to generate higher propulsive forces. Tandem flapping wings have optimal phase patterns depending on the flight condition, which is also in agreement with the results presented by Diana ${ }^{30}$.

The pitching angles of fore- and hind-wings in the two flight modes are illustrated in Fig. 12. This figure shows that the magnitude of the pitching angle are different for these two modes, with lower pitching amplitude in level flight $\left(\eta_{1}\right)$ than in accelerating flight $\left(\eta_{2}\right)$, as illustrated in Fig. 12(c). However, the changes of the pitch angle $\eta$ on each stroke for both flight modes are found 


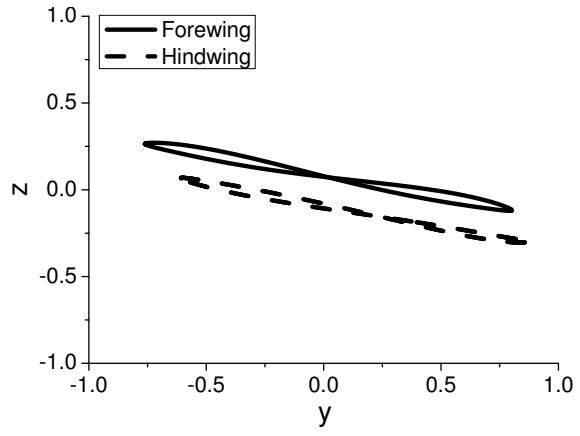

(a) $V=0.25 \mathrm{~m} / \mathrm{s}$.

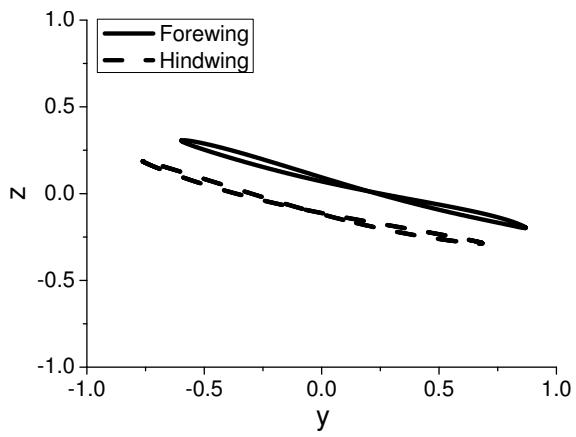

(c) $V=0.75 \mathrm{~m} / \mathrm{s}$.

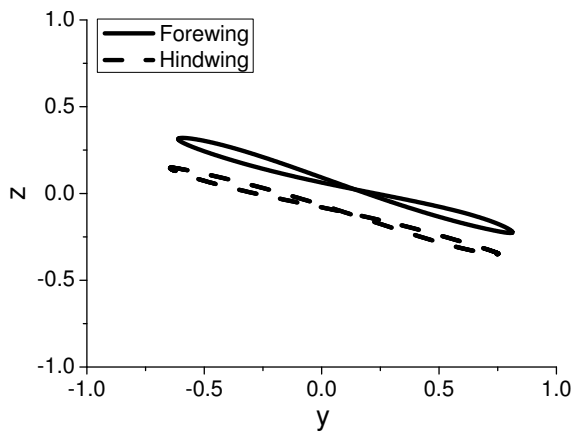

(e) $V=1.25 \mathrm{~m} / \mathrm{s}$.

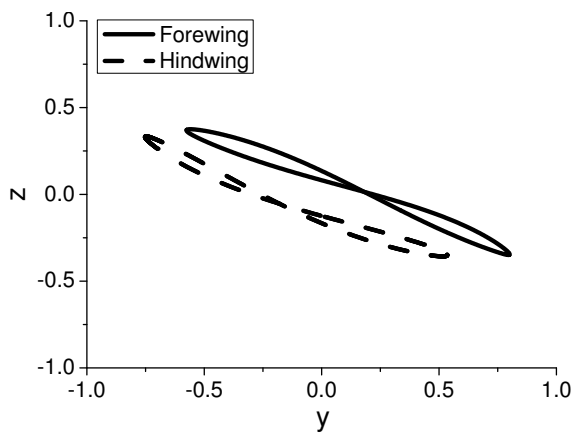

(g) $V=1.75 \mathrm{~m} / \mathrm{s}$.

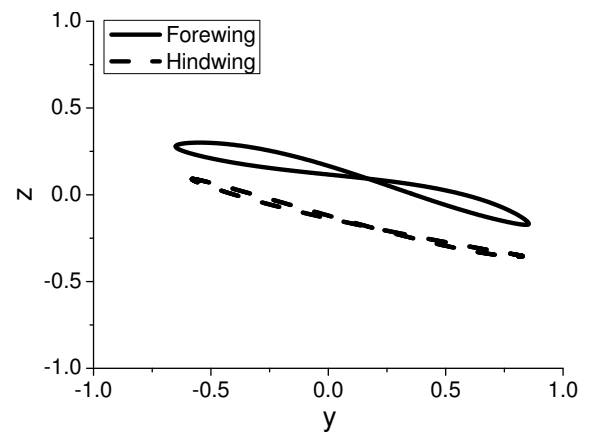

(b) $V=0.50 \mathrm{~m} / \mathrm{s}$.

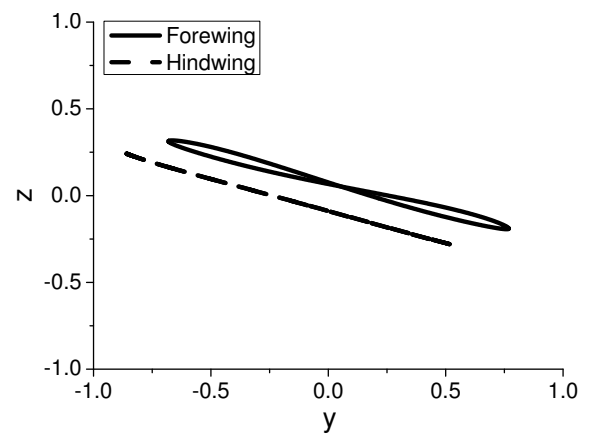

(d) $V=1.00 \mathrm{~m} / \mathrm{s}$.

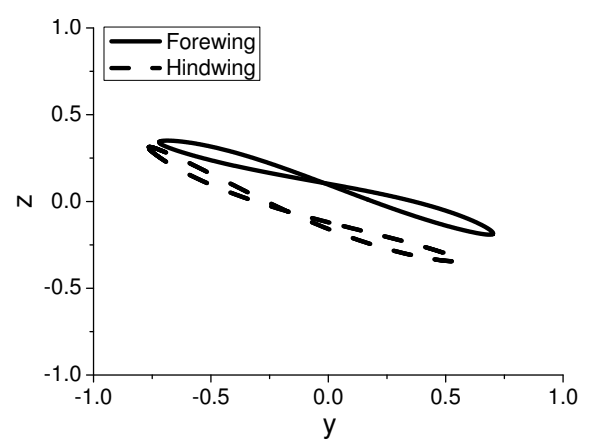

(f) $V=1.50 \mathrm{~m} / \mathrm{s}$.

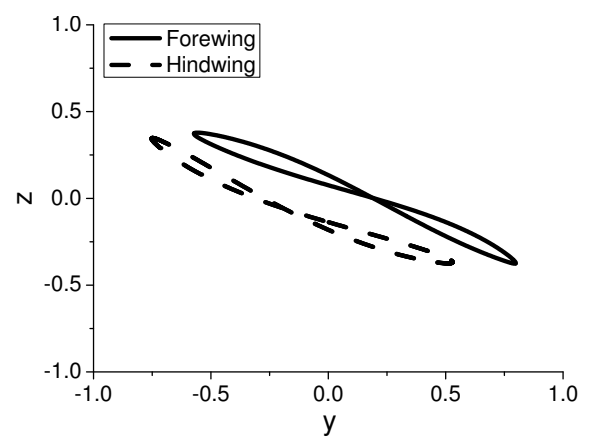

(h) $V=2.00 \mathrm{~m} / \mathrm{s}$.

Figure 9: Simulated wingtip paths relative to the wing base for level flight. The axes are normalized to wing length. 


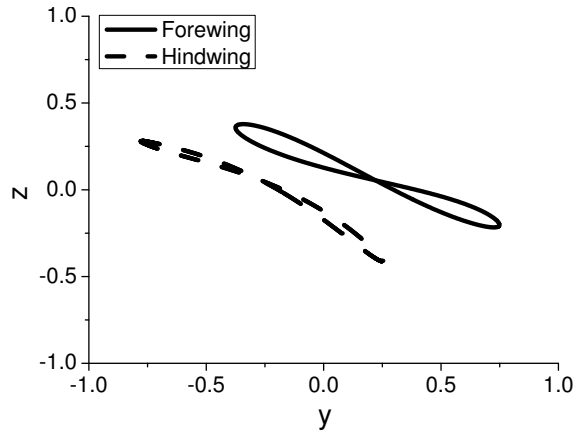

(a) At $P / W=50 W / k g$.

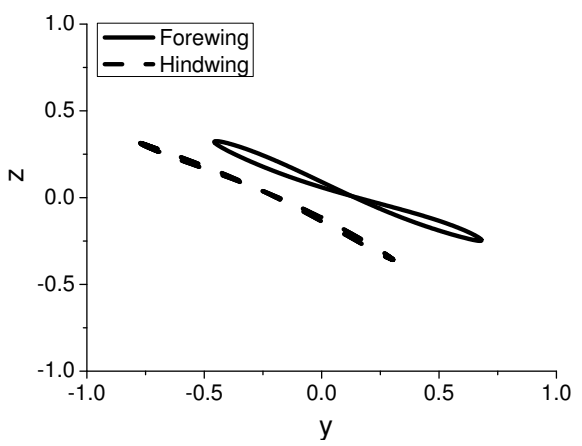

(c) At $P / W=70 W / k g$.

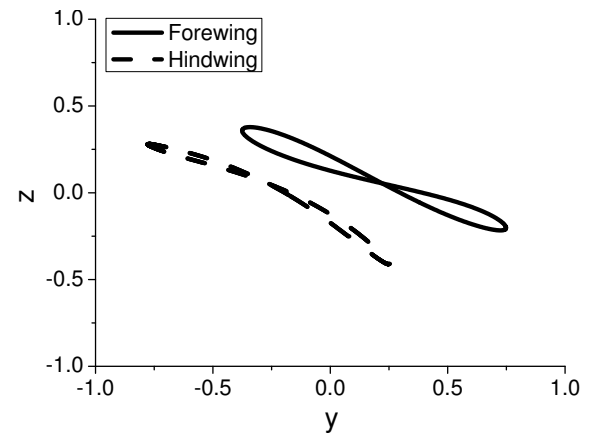

(b) At $P / W=60 \mathrm{~W} / \mathrm{kg}$.

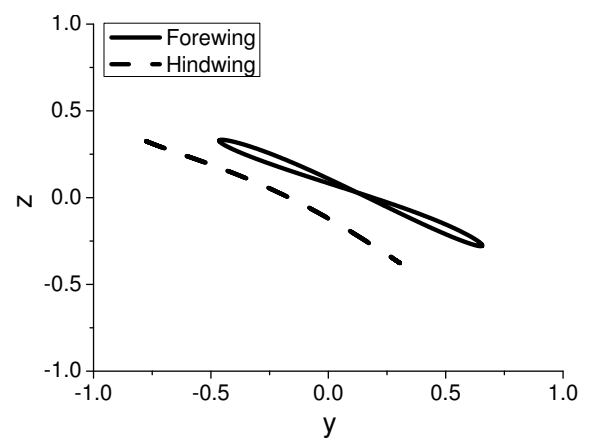

(d) At $P / W=80 W / k g$.

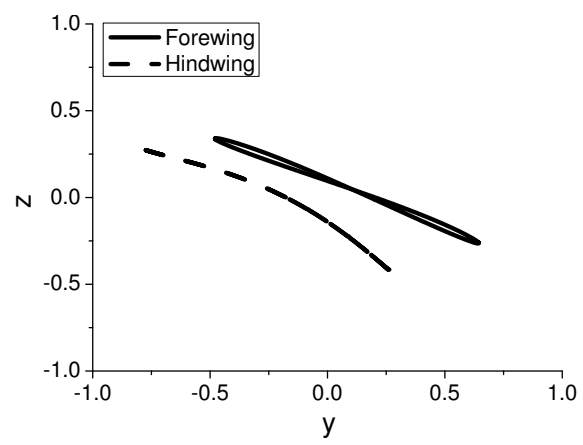

(e) At $P / W=90 W / k g$.

Figure 10: Simulated wingtip paths relative to the wing base for accelerating flight. The axes are normalized to the wing length.

the same; both start with lower $\eta$ during the first half-stroke (or down-stroke), $0<$ cycle $<0.5$. This is because during the down-stroke the wing moves in the direction of the flight and provides higher lift. During the upstroke the inflow is reduced. In this instance, a larger pitch angle is required to compensate for the reduction of the relative inflow. The changes in angle of attack and the relative velocity during down-stroke and upstroke are illustrated in Fig. 13. The changes in the wing kinematics $(\phi$ and $\eta)$ are in line with experimental studies $9 ; 31 ; 32$. 


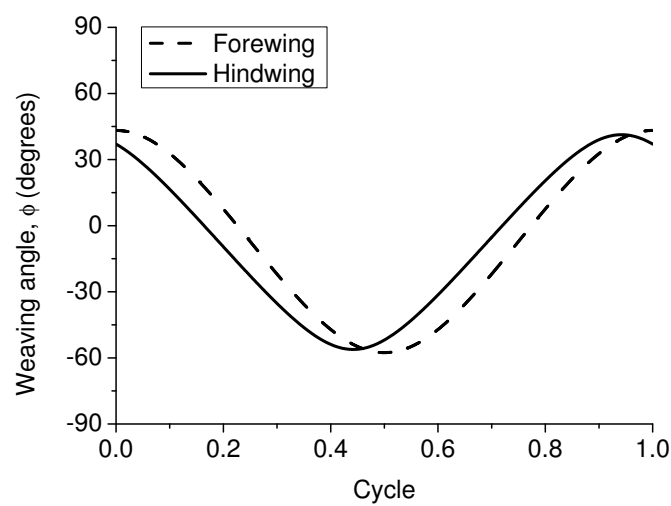

(a) Level flight, $V=1.25 \mathrm{~m} / \mathrm{s}$.

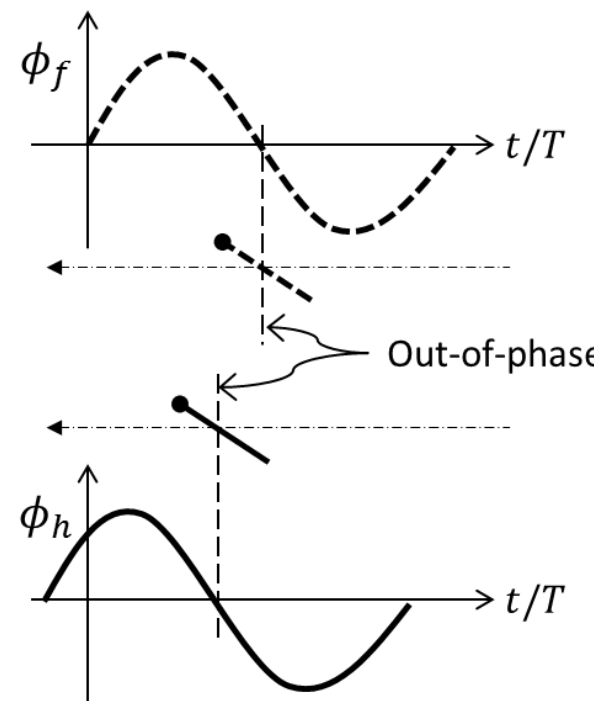

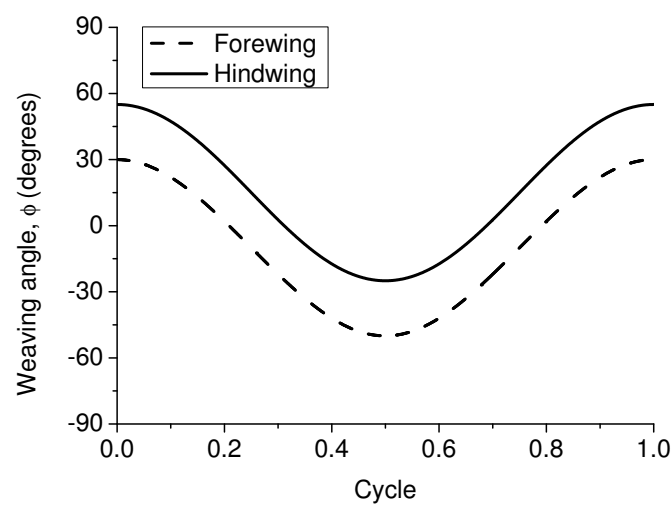

(b) Accelerating flight, $P / W=60 \mathrm{~W} / \mathrm{kg}$.

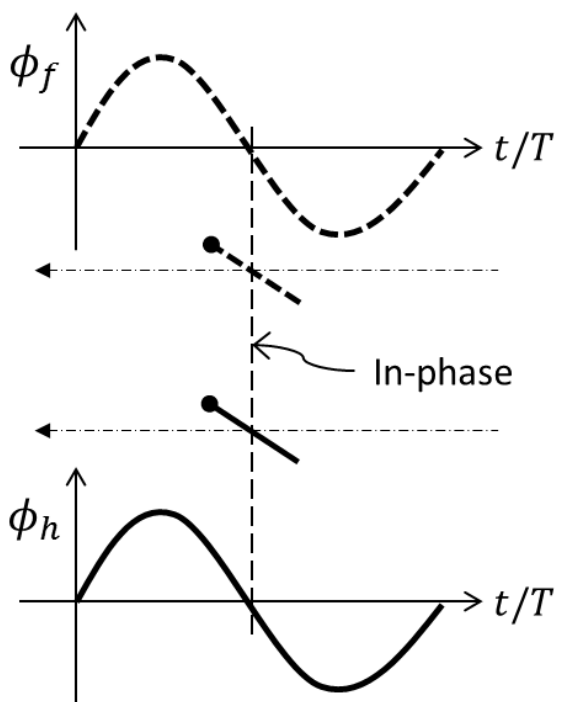

(c) Illustration on the changes of phase pattern. Level flight (left) and accelerating flight (right).

Figure 11: Simulated weaving angle of fore- and hind-wing in two flight modes.

\section{Wing Shape Analysis}

Furthering from the analysis of the tear-drop wing shape, a comparison of flight performance in level and accelerating flight between the tear-drop and real wing is presented; the wings have equal area and wing span. The kinematics of both wings is optimized for maximum propulsive efficiency in level flight, and maximum acceleration for an accelerating flight. The tear-drop and real wing shapes are illustrated in Fig. 14. 


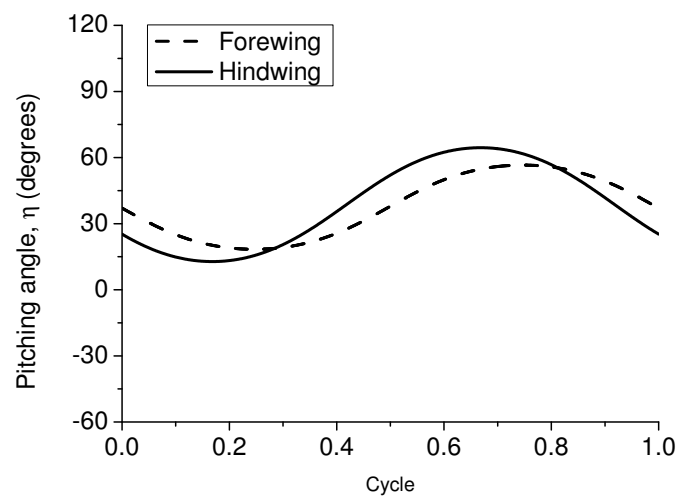

(a) Level flight, $V=1.25 \mathrm{~m} / \mathrm{s}$.

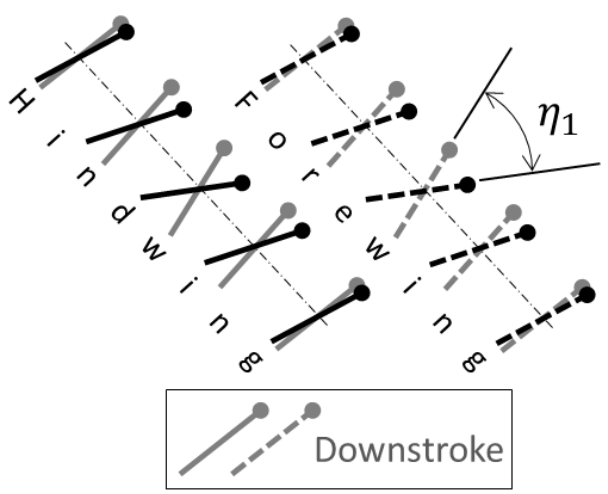

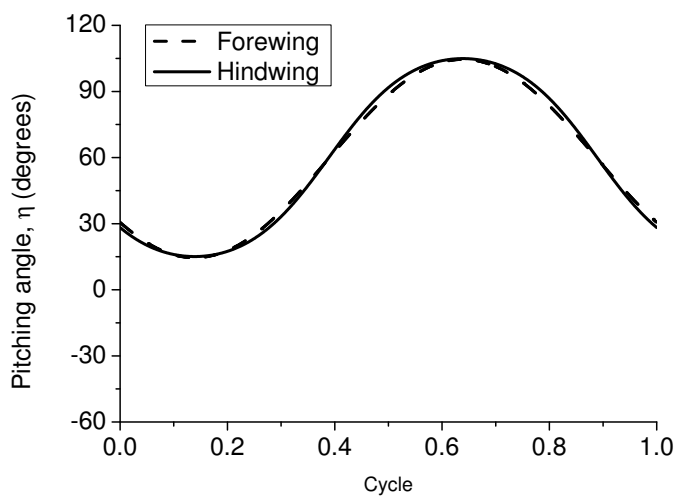

(b) Accelerating flight, $P / W=60 \mathrm{~W} / \mathrm{kg}$.

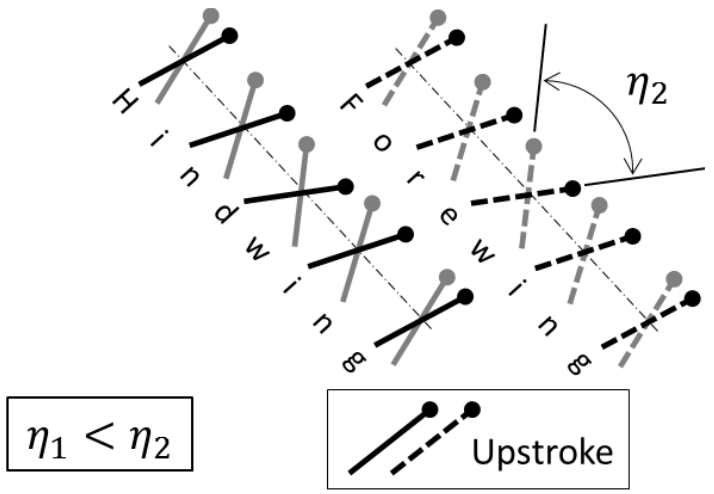

(c) Illustration on the changes of pitching amplitude. Level flight (left) and accelerating flight (right).

Figure 12: Simulated pitching angle of fore- and hind-wing in two flight modes.

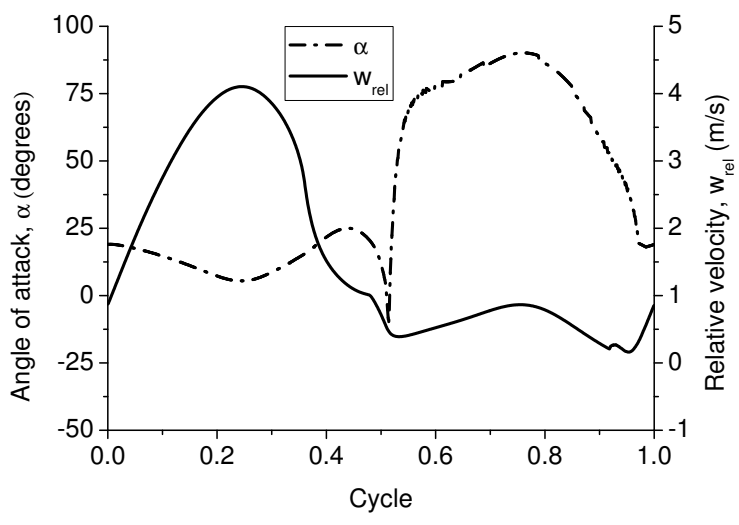

(a) Fore-wing.

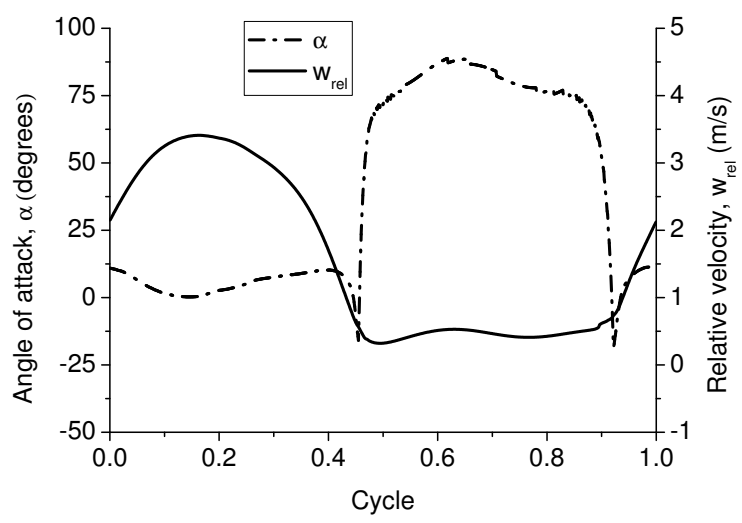

(b) Hind-wing.

Figure 13: Changes in angle of attack and relative velocity (level flight). 

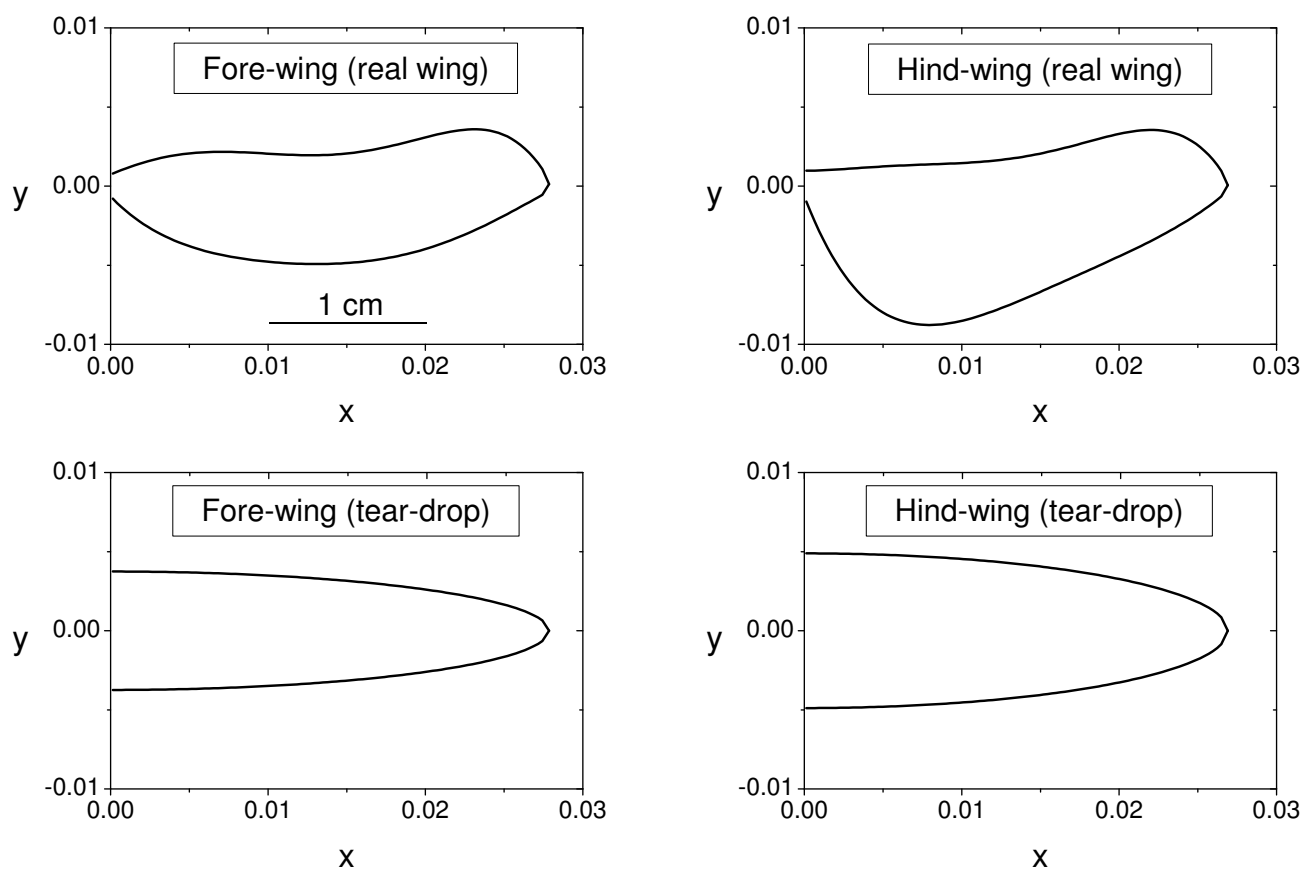

Figure 14: The tear-drop and real wing shapes.

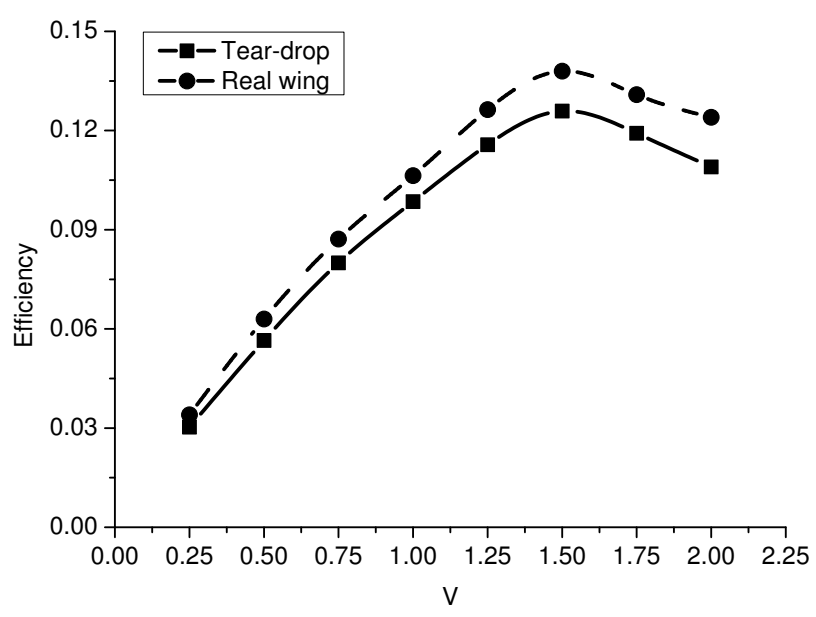

Figure 15: Flight efficiency with two wing shapes.

Figure 15 shows that the level flight efficiency of the real wing shape is higher than the tear-drop wing shape over the range of speeds. With the upper limit increases of up to $\sim 12 \%$ at $2.0 \mathrm{~m} / \mathrm{s}$. The efficiency of the real and the tear-drop peaks at $V=1.50 \mathrm{~m} / \mathrm{s}$. The magnitude of acceleration with the real wing is slightly higher than that of the tear-drop wing over the range of available 


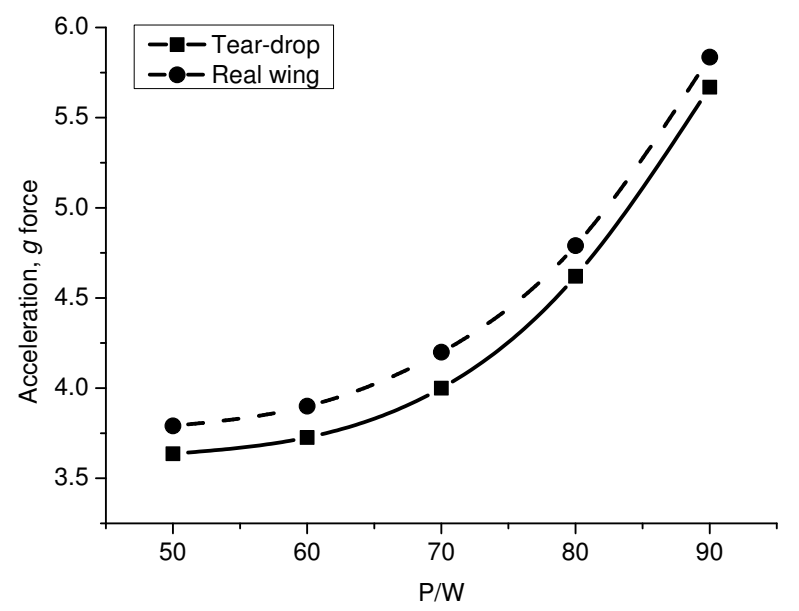

Figure 16: Maximum attainable acceleration with tear-drop and real wing shapes.

power, Fig. 16. This is attributed to a larger chord on the mid-section, as shown in Fig. 14.

\section{Conclusions}

An aerodynamic propulsion model has been developed for tandem flapping wings. Our aim was to study the propulsive characteristics in level and accelerated flight of an insect-size vehicle. The model proposed accounts for flow interference between fore- and hind wing. Inflow corrections have been introduced in the direction normal to the stroke plane. The propulsion model was coupled with an independent numerical optimization capable of handling multiple-parameters disjoint search spaces. The stroke optimization was demonstrated for cases with 28 independent parameters.

The changes in power at each flight speed can be correlated with the changes of the wing kinematics. The predicted level flight efficiency is in agreement with the experimental results of flight muscle efficiency. The maximum attainable acceleration is found to increase with the size of the flight muscle (or power available).

Through the analysis of the wing kinematics, it is shown that the wings will flap out-of-phase to fly efficiently in level flight. However, to obtain maximum acceleration, the wings flap in phase. This result is in agreement with observations of dragonflies in nature.

A separate analysis addressed the role of different wing shapes (tear-drop and dragonfly wing planforms). The results indicate that the real wing shape has better propulsive efficiency and acceleration than the tear-drop wing. Interdependencies between the flapping kinematics, the wing shape and the wing structure have strong influence on the optimal stroke. 


\section{Acknowledgments}

The authors would like to acknowledge the Ministry of Higher Education Malaysia (MOHE) and Universiti Putra Malaysia (UPM) for offering the PhD scholarship for Faisal AHM under the academic training scheme (SLAI).

\section{References}

[1] May ML. Dragonfly flight: power requirements at high speed and acceleration. J. Experimental Biology, 158:325-342, 1991.

[2] Rüppell G. Kinematic analysis of symmetrical flight maneuvers of odonata. J. Experimental Biology, 144:13-42, 1989.

[3] Reavis MA and Luttges MW. Aerodynamic forces produced by a dragonfly. AIAA Journal, 88-0330:1-13, 1988. DOI:10.2514/6.1988-330.

[4] Alexander D. Unusual phase relationships between forewings and hindwings in flying dragonflies. J. Experimental Biology, 109:379-383, 1984.

[5] Azuma A and Watanabe T. Flight performance of a dragonfly. J. Experimental Biology, 137:221-252, 1988.

[6] Marden JH. Bodybuilding dragonflies: Costs and benefits of maximizing flight muscle. Physiological Zoology, 62(2):505-521, 1989.

[7] Isogai K, Fujishiro S, Saitoh T, Yamasaki M, , and Matsubara M. Unsteady three-dimensional viscous flow simulation of dragonfly hovering. AIAA Journal, 42(10):2053-2058, 2004. DOI:10.2514/1.15899.

[8] Yamamoto M and Isogai K. Measurement of unsteady fluid dynamic forces for a mechanical dragonfly model. AIAA Journal, 43(12):2475-2480, 2005. DOI:10.2514/1.6274.

[9] Hu Z and Deng XY. Aerodynamic interaction between forewing and hindwing of a hovering dragonfly. Acta Mechanica Sinica, 30(6):787-799, 2014. DOI:10.1007/s10409-014-0118-6.

[10] Lan CE. The unsteady quasi-vortex-lattice method with applications to animal propulsion. J. Fluid Mech., 93(4):747-765, 1979. DOI:10.1017/S0022112079002019. 
[11] Tuncer IH and Platzer MF. Thrust generation due to airfoil flapping. AIAA Journal, 34(2):324-331, 1996. DOI:10.2514/3.13067.

[12] Huang H and Sun M. Dragonfly forewing-hindwing interaction at various flight speeds and wing phasing. AIAA Journal, 45(2):508-511, 2007. DOI:10.2514/1.24666.

[13] Broering TM and Lian YS. The effect of phase angle and wing spacing on tandem flapping wings. Acta Mechanica Sinica, 28:1557-1571, 2012. DOI:10.1007/s10409-012-0210-8.

[14] Wang ZJ and Russell D. Effect of forewing and hindwing interactions on aerodynamic forces and power in hovering dragonfly flight. Physical Review letters, 99(14):1-4, 2007. DOI:10.1103/PhysRevLett.99.148101.

[15] Lehmann FO. Wing-wake interaction reduces power consumption in insect tandem wings. Experiments in Fluids, 46(5):765-775, 2009. DOI:10.1007/s00348-008-0595-0.

[16] Platzer M, Jones KD, Young J, and Lai J. Flapping-wing aerodynamics: Progress and challenges. AIAA J., 46(9):2136-2149, Sept. 2008. DOI:10.2514/1.29263.

[17] Minami K, Suzuki K, and Inamuro T. Free flight simulations of a dragonfly-like flapping wingbody model using the immersed boundary-lattice Boltzmann method. The Japan Society of Fluid Mechanics, 47(015505):1-17, 2015. DOI:10.1088/0169-5983/47/1/015505.

[18] Warkentin J and DeLaurier J. Experimental aerodynamic study of tandem flapping membrane wings. J. Aircraft, 44(5):1653-1661, 2007. DOI: 10.2514/1.28160.

[19] Faisal AHM and Filippone A. Aerodynamic model for insect flapping wings with induced flow effect. J. Aircraft, in-press. DOI: 10.2514/1.C033382.

[20] Kennedy J. Particle swarm optimization. Encyclopedia of Machine Learning, pages 760-766, 2010. DOI:10.1007/978-0-387-30164-8.

[21] Wakeling JM and Ellington CP. Dragonfly flight II: Velocities, accelerations and kinematics of flapping flight. J. Experimental Biology, 200(3):557-582, 1997.

[22] Berman GJ and Wang ZJ. Energy-minimizing kinematics in hovering insect flight. J. Fluid Mech., 582(1):153-168, 2007. DOI:10.1017/S0022112007006209. 
[23] Usherwood JR and Ellington CP. The aerodynamics of revolving wings II. Propeller force coefficients from mayfly to quail. J. Experimental Biology, 205(11):1565-1576, 2002.

[24] Taha HE, Hajj MR, and Beran PS. State-space representation of the unsteady aerodynamics of flapping flight. Aerospace Science and Technology, 34:1-11, 2014. DOI:10.1016/j.ast.2014.01.011.

[25] Gravish N, Peters JM, Combes SA, and Wood RJ. Collective flow enhancement by tandem flapping wings. Physical Review letters, 115(188101):1-5, 2015. DOI:10.1103/PhysRevLett.115.188101.

[26] Stanford B, Kurdi M, Beran P, and McClung A. Shape, structure, and kinematic parameterization of a power-optimal hovering wing. J. Aircraft, 49(6):1687-1699, 2012. DOI:10.2514/1.C031094.

[27] Wakeling JM and Ellington CP. Dragonfly flight III: Velocities, lift and power requirements. J. Experimental Biology, 200(3):583-600, 1997.

[28] Mazaheri K and Ebrahimi A. Experimental investigation on aerodynamic performance of a flapping wing vehicle in forward flight. J. Fluids \& Structures, 27:586-595, 2011. DOI:10.1016/j.jfluidstructs.2011.04.001.

[29] Ellington CP. Power and efficiency of insect flight muscle. J. Experimental Biology, 115:293$304,1985$.

[30] Diana RG, Jain P, Centero M, Weinreb A, and Thiria B. Four-winged flapping flyer in forward flight. in Selected Topics of Computational and Experimental Fluid Mechanics, Environmental Science and Engineering, Springer International Publishing Switzerland, Part 1:147-158, 2015. DOI:10.1007/978-3-319-11487-3_8.

[31] Seshadri P, Benedict M, and Chopra I. Understanding micro air vehicle flapping-wing aerodynamics using force and flowfield measurements. J. Aircraft, 50(4):1070-1087, 2013. DOI:10.2514/1.C031968.

[32] Razak NA and Dimitriadis G. Experimental study of wings undergoing active root flapping and pitching. J. Fluids 85 Structures, 49:687-704, 2014. DOI:10.1016/j.jfluidstructs.2014.06.009. 